Salam, M., Forsythe, P., and Killen, C. (2019). "Exploring Interdisciplinary Collaboration in the Detailed Design Phase of Construction Projects". In: Proc. $27^{\text {th }}$ Annual Conference of the International. Group for Lean Construction (IGLC), Pasquire C. and Hamzeh F.R. (ed.), Dublin, Ireland, pp. 761-772. DOI: https://doi.org/10.24928/2019/0149. Available at: 〈www.iglc.net>.

\title{
EXPLORING INTERDISCIPLINARY COLLABORATION IN THE DETAILED DESIGN PHASE OF CONSTRUCTION PROJECTS \\ Mona Salam ${ }^{1}$, Perry Forsythe ${ }^{2}$, and Catherine Killen ${ }^{3}$
}

\begin{abstract}
The foundation for successful collaboration in the detailed design phase of construction projects is aligning the knowledge and views of designers and contractors. In such design development meetings, architects, consultants, main contractor, subcontractors, and client representatives face several challenges in moving from conceptual designs to a documented set of shop drawings. This phase represents the peak of participants' interactions including exploring and refining design solutions, explaining and reflecting on each other's ideas and concerns, and negotiating design and cost decisions. Collaboration is often presented in the literature as practices that provide the platform for successful interaction and the achieved outcomes, but with minimal concern about actual interactive processes. Theoretically, collaboration has been studied from a variety of perspectives grouped into normative and practice-based approaches that have enhanced the research field at the inter-organisational macro-level, but there is no consensus on a framework to measure collaboration empirically in the field. Therefore, the aim of this paper is to explore the common themes describing interdisciplinary collaboration in the literature and develop a framework explaining the conceptual relationship between them. The proposed framework provides a preliminary step towards understanding the dynamic nature and stages of the interdisciplinary collaboration in the detailed design phase.
\end{abstract}

\section{KEYWORDS}

Collaboration, lean construction, detailed design, interdisciplinary teams

\section{INTRODUCTION}

Since the Latham (1994) and Egan (1998) reports in the 90s, collaboration within construction teams has been understood as pivotal for improving efficiency and

1. PhD Candidate, School of Built Environment, University of Technology Sydney, Australia, Mona.AbdAl-Salam@uts.edu.au

2. Professor, School of Built Environment, University of Technology Sydney, Australia, Perry.Forsythe@uts.edu.au

3. Associate Professor, School of Built Environment, University of Technology Sydney, Australia, Catherine.Killen@uts.edu.au 
productivity, albeit that recent statistics suggest little or no improvement in productivity over the past 20 years (ABS 2018). Several scholars have stressed the need for effective collaboration between designers and contractors to address fragmentation which is an ongoing problem in the construction industry (Gunasekaran \& Love 1998; Koskela 1992). Complex construction projects often involve the creation of temporary interdisciplinary teams that are made up of participants drawn from a wide range of disciplines and organisations. Participants from diverse backgrounds have different values, attitudes and goals, which affect their interactions and their ability to resolve conflicts, communicate effectively, and exchange knowledge (Baiden, Price \& Dainty 2006; Emmitt 2010). Collaboration in this setting demonstrates how participants tend to work together to find better, more streamlined ways of delivering what the client needs despite their diverse perspectives.

The interdisciplinary collaborative process was defined by Gray's seminal work (1989, p. 5) as "the process through which parties who see different aspects of a problem can constructively explore their differences and search for solutions that go beyond their limited vision of what is possible". To reach this level of synergy in construction projects, interdisciplinary participants work towards achieving a mutual understanding by exchanging knowledge and information to jointly deliver the best solution that meets their common goal of maximising client value. These collaborative efforts are different from other interactive forms such as cooperation and coordination; inter-organisational cooperation is not commonly related to aligning a vision or goal and information is only shared when needed (Mattessich \& Monsey 1992) and coordination requires a more formal planning approach than cooperation because it focuses on the alignment of goals and sharing some risks among groups (Schöttle 2014). The relationship between participants is more intense and stronger in collaboration as a shared goal and culture based on trust exists among participants that enable them to tackle project constraints and maximise outcomes.

Several scholars examined the enhancement of collaboration through non-traditional procurement approaches such as the integrated project delivery (IPD) (Franz \& Leicht 2012; Kent \& Becerik-Gerber 2010; Thomsen et al. 2009) and lean project delivery (LPS) (Ballard 2008; Forbes \& Ahmed 2010) that fundamentally focus on the early involvement of contractors in the design process to improve constructability and cost estimation, and reduce design iterations. Similar benefits are achievable in a more common project delivery method used globally and in Australia, the design-build approach, where contractors provide better value for money by working closely with the designers. Even though this is an ideal scenario, not all construction projects have perfect collaboration throughout the whole design phase because of opposing interests between architects and designers, and contractors. At the conceptual design phase, contractors' constructability information allows the designers to be more informed about cost ramifications of their design options. However, there is a change point as the design progress through the detailed design phase because contractors' focus becomes cost and schedule centric, which contest with creative and innovative nature of architects' work (Forbes \& Ahmed 2010; Sødal 2014). Given the long duration of the whole design process, it is unrealistic to study all the design phases in detail. Therefore, the detailed design phase has been chosen to be the central focus of this 
research because it represents the peak of designers and contractors' interactions to develop the design intent to be a physically achievable reality.

\section{THE NEED FOR EFFECTIVE COLLABORATION IN THE DETAILED DESIGN PHASE OF PROJECTS}

Interdisciplinary teams face a number of challenges that affect their ability to collaborate effectively. Common problems are poor communication between members, deficient or missing information for making timely decisions, and lack of coordination between various design disciplines (Mryyian \& Tzortzopoulos 2013). These process problems in collaboration are reflected in the quality of design documents produced, which causes unnecessary design iterations that do not add value to clients or subsequent disciplines in the supply chain (Ballard 2000; Ballard \& Koskela 1998). For instance, a recent study on the cost of quality failures (deviation, defects, nonconformance and rework) found that design change in scope, errors and omissions in documentation contributed to $13.9 \%$ of the cost of nonconformance (Love, Teo \& Morrison 2017). Similar design documentation problems are demonstrated in major trade packages such as steel and concrete causing delays on site that have associated costs. Case studies have illustrated these problem in missing information on the exact location of penetrations in steel beams to accommodate mechanical, electrical and plumbing (MEP) services (Smith 2010), and crowded rebar connections that are only realised at later stages of the detailed design phase causing negative design iterations (Luth 2011). These problems show that designers need to be mindful that the information they create will be used by many other parties such as main contractors, subcontractors and fabrication suppliers.

Lean philosophy in construction emphasises that time should be spent upfront in the design process because once construction has begun, it is expensive to change the design (Ballard 2008; Forbes \& Ahmed 2010). Lean management strategies rely on a comprehensive model that brings project process under control, improve information flow, recognise and cope with uncertainty, and deliver value to the client (Koskela 1992). These strategies advocate integrating the design and construction phases to realise these values and to ensure that design can be produced cost effectively (Koskela et al. 2002). Incorporating construction details in the design process requires a systematic approach as it comprises two knowledge groups: product (design) and process (sequencing and plans) knowledge (Ballard \& Koskela 1998). A number of solutions have been proposed to help merging design and construction knowledge such as developing frameworks that detail design information required at each stage of the design phase (Pulaski \& Horman 2005). Another approach incorporates use of boundary objects as full-scale mockups of the proposed building to thoroughly test constructability, which helps understand the complexity of the design intent and enhances inter-organisation cooperation (Naar, Nikolova \& Forsythe 2016). 


\section{UNVEILING COLLABORATION DIMENSIONS IN THE DESIGN AND CONSTRUCTION LITERATURE}

Collaboration between designers and contractors in the design phase is not an easy or straightforward process. Their diversity brings differences in objectives and interests. Their collaboration is expected to involve different interaction patterns including exploring and testing design ideas, explaining and reflecting on each other's ideas and concerns, and negotiating design and cost decisions. Dimensions describing interdisciplinary collaborative practices in the detailed design phase are identified from a review of the design and construction literature particularly lean construction. Some of these dimensions represent factors likely to enhance collaborative efforts, others focus on active process, and the rest are concerned with collaborative outcomes.

\section{Enhancing dimensions}

Some recurring themes in the literature tend to cluster around enhancement that help in preparing the suitable environment for collaboration to take place such as co-locating team members in one common space. The term co-location is sometimes used interchangeably with the practice of using a "big room" equipped with tables and screens to project 2D drawings and 3D models. Co-location maximises the opportunities to collaborate and interact easily to solve problems that occur throughout the design phase and increases the desire to discuss project issues in real time (Alarcon, Christian \& Tommelein 2011; Denerolle 2013). However, physically co-locating participants involved in the detailed design phase might not be the optimum solution for all firms involved in a project because of cost and time implications. To mitigate this, design development meetings are suggested at regular intervals (e.g. weekly), especially for newly formed teams. .

Sharing information among participants is the foundation for coordinating design and project information. It is particularly relevant to the detailed design phase because participants need to access the most up-to-date information about design progress to evaluate design solutions and respond to requests for information (RFIs) (Luth 2011). This collaboration dimension can best be described as a common means of accessing passive project information. This classification is needed to differentiate between project information and another type of active information that participants exchange in collaborative design discussion including, for example, inquiries about design details, dimensions, or structural elements locations.

Defining roles and responsibilities of participants is a key requirement of collaboration because it clarifies participants' contributions in meetings and how the sequence of the design process is expected to unfold (Mattessich \& Monsey 1992). Team diversity is another collaboration facilitator, which is demonstrated by including main contractors and specialty subcontractors in design discussions at an early stage. This approach merges experiences and speeds up responses to technical inquiries. This dimension was evident in applying lean tools such as set-based design, and choosing by advantage (Arroyo, Tommelein \& Ballard 2012) where the process of exploring design alternatives included a rigorous analysis of proposed options carried out by designers, the contractor and relevant subcontractors such as steel fabricators and placers. 


\section{Active process dimensions}

Another group of themes explaining the active process dimensions is also highlighted in the literature as important for collaboration. Aligning cost incentives brings together participants' interests when discussing design options to improve value (Zimina, Ballard $\&$ Pasquire 2012). Incentive alignment methods have different forms such as bonuses linked to adding value to the project, rewards for innovation and outstanding performance, and bonuses based on improved quality. These methods are feasible in the presence of formal relational agreements (Lichtig 2010). In other traditional procurement methods where contractors are not engaged earlier in the project, or where a number of separate contracts are used, these bonus approaches are harder to implement. However, aligning the views of designers and contractors in the same discipline can still be achieved through regular workshops allowing them to develop a common understanding of each other's technical and management constraints and collectively find suitable solutions (Denerolle 2013).

Collective decision-making is another dimension describing collaborative working processes. It refers to the involvement of participants who possess the required skills and knowledge to address a wider range of potential solutions before agreeing on a specific design solution (Arroyo, Tommelein \& Ballard 2012). Decisions are more accurate and rationalised if participants who have the decision-making authority are present in detailed design meetings and engage constructively without having to refer to their superiors. Examples of sound decisions are illustrated by bringing together designers and contractors to investigate suitable design and installation solutions for main structural frames (Nguyen, Lostuvali \& Tommelein 2009) and choosing between different beam-column joint alternatives to address construction constraints (Parrish et al. 2007).

Interactive coordination is a collaboration dimension describing working processes. It involves engaging downstream stakeholders in discussions to encourage innovative thinking to pursue improvements in the construction processes on site (Alarcon, Christian \& Tommelein 2011). Contractors can contribute to the discussion by providing their input on constructability, which allows designers to make better decisions with fewer design iterations. Examples of contractors' feedback on technical problems include evaluating prefabrication options, solving MEP clashes, and testing structural frame installation before construction begins to improve workflow on site (Luth 2011). These benefits of accessibility and comprehensibility of design information have been associated with the use of Building Information Modeling (BIM) (Aram, Eastman \& Sacks 2013; Azhar 2011). Several case studies documented the implementation of BIM in different design disciplines. For instance Arayici et al. (2012), detailed the substantial influence of BIM in architectural practices in terms of better communication with other stakeholders and refining design options. The advantages of BIM in clash detection of MEP services were prominent in improving coordination between designers and contractors in terms of exploring prefabrication options and reducing the number of design changes (Staub-French \& Khanzode 2007). While these studies provide valuable insights into the adaption of digital technology in the AEC industry, their contribution in studying the interactive collaboration focused on quantifying the achieved outcomes. Construction projects are governed by 
different variables, for example, procurement and delivery methods, size and complexity of the building, and diversity of organisations involved, which increase the difficulty of linking collaboration solely to technology applications. However, a common theme in these approaches is that BIM is a progressive digital tool that mediates interactive collaboration between participants involved in the design development phase.

\section{Outcomes dimensions}

Value for money is regarded as the main collaboration outcome because it represents the client's objective, which is achieving the best design for the money spent. This concept is present in any procurement type because the client is the main principal who brings participants together in construction projects. Other outcomes are also legitimate, for instance, designers work towards achieving the design intent if the proposed building has special aesthetic features. Similarly, main contractors focus on controlling common project management constraints such as program timeframes and budget limits, while accommodating design requirements. Subcontractors are keen to get instant responses to their design inquiries to reduce the time spent waiting for processing RFIs, and receive faster decisions on their proposed design options (Denerolle 2013). Lastly, trust in expertise and capabilities among participants is a collaboration outcome dimension. It develops over time after a number of successful collaborative interactions among participants occur and hence creates a sense of belonging to the team that encourages team members to generate ideas and collaboratively solve problems (Baiden, Price \& Dainty 2006). However, in construction projects, participants have insufficient time to develop trust due to time pressures and limited experience working together, which might affect the negotiation and interaction in meetings. For instance, participants might feel unsure that their concerns were considered or adequately discussed before decisions were made, which could extend negotiations on critical design issues (Emmitt 2010).

Based on the previous discussion, the above dimensions are themes identified as being important for collaborative interactions in interdisciplinary teams. Even so, what is missing from the discussion about enhancing, active and outcome dimensions is a framework that pulls them all together in a mutually explanatory way.

\section{THE LACK OF A HOLISTIC FRAMEWORK FOR EXPLAINING COLLABORATION}

This section provides a brief overview of collaboration frameworks from the interorganisational domain. The seminal work done by Thomson (2003) in investigating the roots of collaboration theoretical perspectives identified two literature streams, the normative approach that focuses on incorporating collaboration into strategy design, and the practice-based approach that is concerned more with identifying collaboration antecedents. The normative stream searches for ways to improve existing organisation networks to cope with increasingly complex problems. Examples of theoretical perspectives resembling this approach include organisation networks (Powell 1990), and collective action (Ostrom 1998). This normative approach views collaboration as a strategy for survival to cope with the growing needs for new organisation forms, thus they were concerned with what ought to be with little attention to how the collaborative process takes place. 
The practice-based stream builds on the normative literature and adds new theoretical perspectives that encouraged working towards theory development based on collaborative perspectives. This literature stream introduced frameworks focusing on interorganisational relationships for combining resources (Ring \& Van de Ven 1994) and collaborative perspective that advocates diversity in skills to deal with highly uncertain complex problems (Gray 1989; Huxham 1996; Thomson \& Perry 2006; Wood \& Gray 1991), which adds to the concept of stakeholders' interdependence (Thomson 2003, p. 90). These scholars share a view that work done on collaboration focus more on antecedents leaving the active process the least understood and often presented as outcomes. However, each of these different frameworks addresses part of the collaborative processes; Ring \& Van (1994) framework is better at explaining the cyclic link between negotiation interactions, commitments, and implementation through an iterative assessment of these three processes. Another framework goes deeper in explaining the processes of collaboration discussions (Gray 1989). Thomson \& Perry (2006) build on these frameworks and identifies collaboration administration dimensions that managers need to know beforehand managing the tension inherited in negotiations among participants. While these theoretical perspectives do not provide consensus or offer a holistic framework to measure collaboration empirically to move towards theory building (Thomson 2003), these studies provide a rich research foundation for investigating interdisciplinary collaboration and support the creation and adaptation of frameworks to explore interactive collaboration processes (discussed in the previous section).

\section{Development of a framework explaining collaborative processes in the detailed design phase of construction projects}

The above discussion supports the proposition that there is a gap concerning a holistic theoretical framework that helps to explain collaborative processes. To reconcile this gap, the study looked at three aspects that were found important for developing a framework that brings together the collaborative dimensions identified earlier. These aspects are the presence of antecedents, dissecting the collaborative process, and the need for participants' diversity. Given that the frameworks explained in the above section investigated collaboration at a macro-level, the antecedents identified focused on a reciprocal need for resources between organisations to deal with complex problems (Thomson 2003, p. 32). However, the dimensions identified earlier as enhancements dimensions demonstrate the concept of antecedents when applied at a micro-level as factors regulating participants' interactions before starting their design discussions. Moving to the collaborative process, Gray's (1989) generic model describing interdisciplinary collaborative efforts was found suitable for adaptation in construction because it relies on a number of key concepts. These concepts view interdisciplinary collaboration as a negotiated process that shapes participants' interaction to reach an acceptable agreement and takes into consideration the need for diversity concept to solve complex problems (Gray 1989, pp. 229, 31). These concepts are evident in construction projects because participants' collaboration revolves around solving design problems to develop the design from conceptual to construction detail level. To achieve this, other design partners, the subcontractors, step in to complete the design, which aligns with the need for diversity concept. In design discussions, several 
negotiations occur to refine proposed design options to achieve design integrity within budget limitations. A representation of Gray's generic model is shown in figure 1 below.

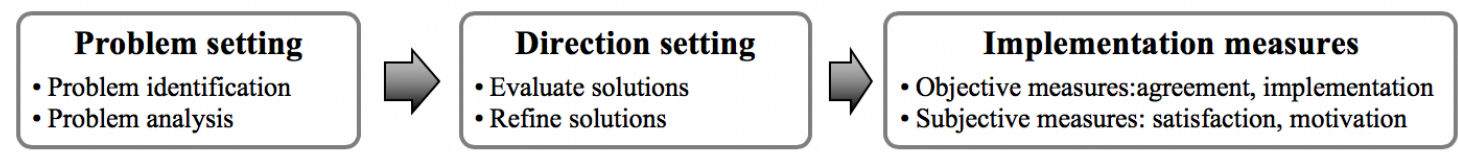

Figure 1 Representation of Gray's model (1989)

Gray's (1989) postulated that collaborative efforts generally proceed through three major phases in a linear fashion: problem setting, direction setting, and implementation. The first problem-setting phase starts with identifying stakeholders then defines the problem by providing a broad analysis to improve the quality of solutions, aligning views during negotiation, and taking each participant's interest into account in agreements. This approach is needed in design discussion because participants need to develop a common understanding of each other concerns regarding the design task they are investigating in terms of design, cost, and program constraints. The second phase is the direction-setting that begins when participants evaluate the proposed solutions and align their interest to reach an agreement on the best solution and consequently explore ways to refine and implement it (Gray 1989, p. 74). To achieve this, both design and construction knowledge needs to be integrated to refine design solutions and explore means of improving constructability. The final implementation phase has two indicators: the first one is objective as it documents if participants reach an agreement and whether it was implemented, while the other indicator is subjective because if participants are not satisfied with the collaborative processes, they are unlikely to accept the outcome (Gray 1989, pp. 256,7). Participants need to experience progressive success to be motivated to sustain their collaborative efforts (Mattessich \& Monsey 1992). This view is relevant in construction projects because they usually have long timeframe to reach completion and the interdisciplinary team is expected to interact collaboratively in weekly or fortnightly meetings throughout the detail design phase.

Given the above discussion, the model presented in figure 1 provides the linear direction of collaborative processes. It is considered beneficial as a broad framework for pulling together the previously discussed collaboration dimensions including enhanced, active and outcome dimensions. However, an outstanding issue concerns how these dimensions fit into this framework. The previous dimension of enhancements does not exist in Gray's model but still seems important because it provides pre-settable features of a collaboration that has yet to take place. Thus, they are considered as the first stage of the framework. The next step focuses on filling the vertical components of the collaborative processes. To do so, collaboration dimensions are rearranged to fit with the description of each phase of the model. The active process is distributed across the first two stages of the model presented in figure 1, the problem and direction settings. The problem setting is the stage where participants are expected to define the problem and align their views to explore possible solutions. Two active process dimensions fit with this description, the interactive coordination and aligning views in cost-related issues. The collective decision-making 
dimension resembles the direction setting phase as participants work towards reaching an agreement on the best solution. Lastly, the outcomes dimensions can be split into objective ones measuring what participants achieved such as value for money, design integrity, and improving working processes. The subjective measure is represented by the developed trust in expertise and capabilities. The arrangement of these dimensions is displayed in the proposed collaboration framework in figure 2.

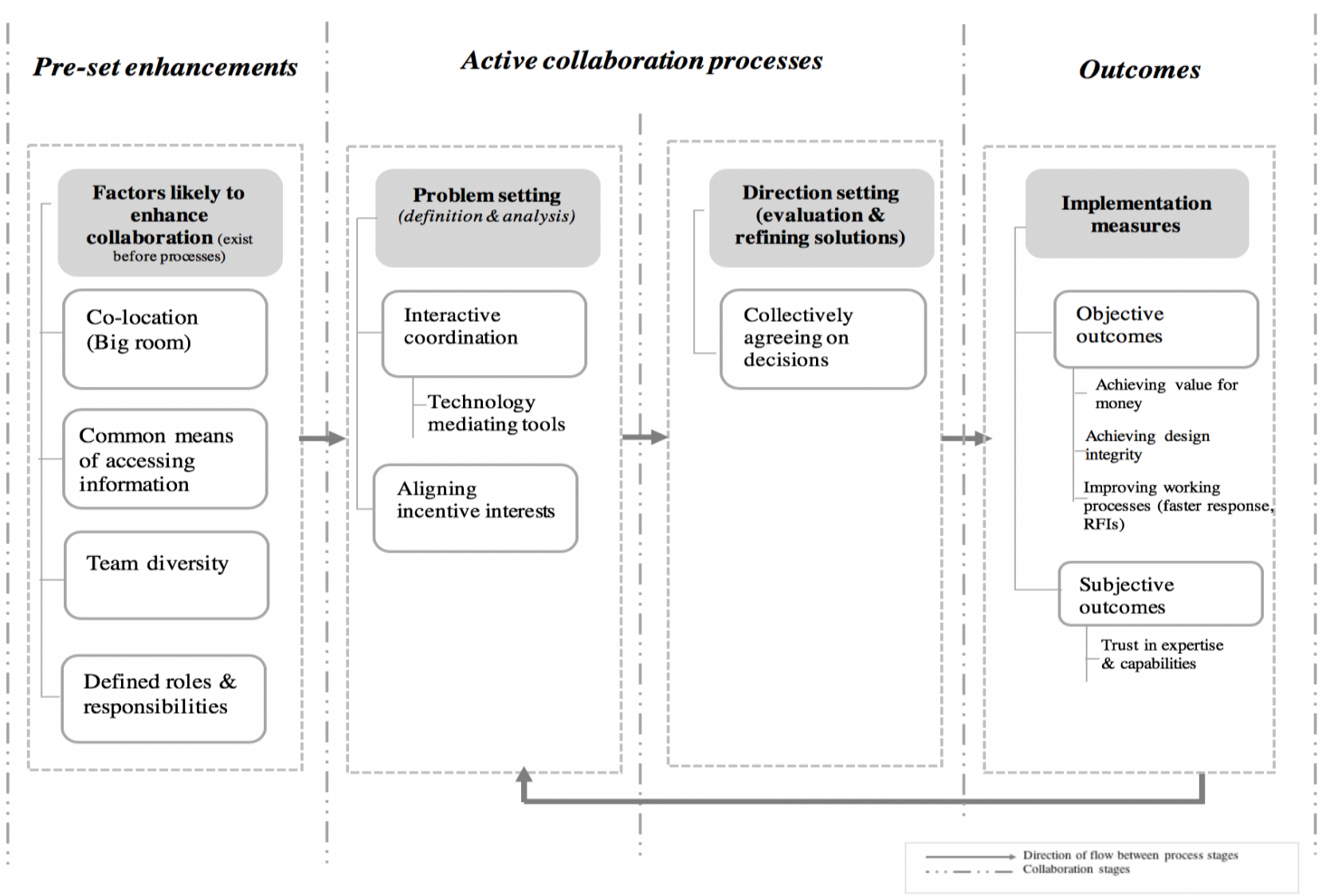

Figure 2 Proposed collaboration framework

The framework in Figure 2 highlights the important, but neglected area of active collaboration processes, what participants actually do in these discussions. Such a framework will assist with the difficult task of measuring collaboration, which is a relatively subjective and unpredictable concept. The subjectivity is strong because the construction industry relies heavily on humans when compared to other industries such as manufacturing. Given the diversity of participants involved in the detailed design phase, a variety of collaboration perspectives are expected to emerge. Collaboration is not a predictable process, as participants in construction projects cannot say in advance that a specific meeting will be collaborative or not. However, participants might expect that a certain task will be difficult to resolve due to design complexity or late changes. In these situations, designers are unsure how other design partners, such as subcontractors, will perceive their ideas or design change request, which might affect their collaboration. 
Aligning with this fluctuation between easier and more difficult design discussions, studies have confirmed that collaboration is not a constant process but changes over time (Thomson \& Perry 2006). Considering these symptoms of collaboration and the gap in the literature in describing collaborative processes, the proposed framework enables a detailed investigation of the collaborative processes by employing a practice-based longitudinal study approach using empirical methods of inquiry. Practice-based studies are particularly applicable in such complex and dynamic settings (Clegg et al. 2018) as they focus on providing a better explanation of what participants actually do in their working practices.

\section{CONCLUSIONS}

The design and construction literature identify a number of dimensions describing collaboration enhancements and outcomes; however, there is a lack of knowledge about actual practices, or what participants do in the active collaboration process. To address this gap, this study builds on the existing theoretical approaches related to inter-organisational relationships by proposing a framework that combines literature findings to explain collaboration. The proposed framework reveals a lack of detail in areas such as problem setting and direction setting suggesting that these could be rich areas for further development and understanding. More research is needed to capture and analyse active collaboration actions in order to profile good and bad collaboration. A longitudinal practice-based approach is proposed to enable studying the events and conditions that encourage or constrain collaborative efforts. The intention for developing this framework is to apply it to empirical case study focusing on participants working practices in design development meetings. Through this study, the framework will provide a holistic means of evaluating the collaboration practices among interdisciplinary project teams and validating the associated outcomes.

\section{REFERENCES}

ABS 2018, Estimates of Industry Multifactor Productivity, 2017-18, Autralian Bureau of $\begin{array}{ll}\text { Statistics } & \text { Canberra2019, }\end{array}$ <https://www.abs.gov.au/ausstats/abs@.nsf/0/E95A0098761C9EC9CA25807D00 172D73? Opendocument $>$.

Alarcon, I., Christian, D. \& Tommelein, I.D. 2011, 'Collaborating with a permitting agency to deliver a healthcare project: Case study of the Sutter Medical Center Castro Valley (SMCCV)', Proc. 19th Annual Conf. Int'l Group for Lean Construction, pp. 402-15.

Aram, S., Eastman, C. \& Sacks, R. 2013, 'Requirements for BIM platforms in the concrete reinforcement supply chain', Automation in Construction, vol. 35, no. 0, pp. 1-17.

Arayici, Y., Egbu, C.O. \& Coates, P. 2012, 'Building information modelling (BIM) implementation and remote construction projects: issues, challenges, and critiques', Journal of Information Technology in Construction, vol. 17, pp. 75-92.

Arroyo, P., Tommelein, I.D. \& Ballard, G. 2012, 'Deciding a sustainable alternative by 'choosing by advantages' in the AEC industry', Proc. 20th Ann. Conf. Int'l. Group for Lean Construction (IGLC), San Diego, CA. 
Azhar, S. 2011, 'Building information modeling (BIM): Trends, benefits, risks, and challenges for the AEC industry', Leadership and Management in Engineering, vol. 11, no. 3, pp. 241-52.

Baiden, B.K., Price, A.D.F. \& Dainty, A.R.J. 2006, 'The extent of team integration within construction projects', International Journal of Project Management, vol. 24, no. 1, pp. 13-23.

Ballard, G. 2000, 'Positive vs negative iteration in design', Proceedings Eighth Annual Conference of the International Group for Lean Construction, IGLC-6, Brighton, $U K$, pp. 17-9.

Ballard, G. 2008, 'The lean project delivery system: An update', Lean Construction Journal, vol. 2008, pp. 1-19.

Ballard, G. \& Koskela, L. 1998, 'On the agenda of design management research', Proceedings IGLC, vol. 98, pp. 52-69.

Clegg, S., Killen, C.P., Biesenthal, C. \& Sankaran, S. 2018, 'Practices, projects and portfolios: Current research trends and new directions', International Journal of Project Management, vol. 36, no. 5, pp. 762-72.

Denerolle, S. 2013, The application of Target Value Design to the design phase of 3 hospitals projects, University of California, Berkeley.

Egan, J. 1998, 'The Egan Report-Rethinking Construction', Report of the Construction Industry Task Force to the Deputy Prime Minister. London.

Emmitt, S. 2010, Managing interdisciplinary projects: a primer for architecture, engineering and construction, Routledge.

Forbes, L.H. \& Ahmed, S.M. 2010, Modern construction: lean project delivery and integrated practices, CRC press.

Franz, B. \& Leicht, R.M. 2012, 'Initiating IPD Concepts on Campus Facilities with a" Collaboration Addendum', Construction Research Congress 2012, pp. 61-70.

Gray, B. 1989, 'Collaborating: Finding common ground for multiparty problems'.

Gunasekaran, A. \& Love, P.E.D. 1998, 'Concurrent engineering: a multi-disciplinary approach for construction', Logistics Information Management, vol. 11, no. 5, pp. 295-300.

Huxham, C. 1996, Creating collaborative advantage, Sage.

Kent, D.C. \& Becerik-Gerber, B. 2010, 'Understanding construction industry experience and attitudes toward integrated project delivery', Journal of construction engineering and management, vol. 136, no. 8, pp. 815-25.

Koskela, L. 1992, Application of the new production philosophy to construction, Stanford University (Technical Report No. 72, Center for Integrated Facility Engineering, Department of Civil Engineering). Stanford, CA.

Koskela, L., Howell, G., Ballard, G. \& Tommelein, I. 2002, 'The foundations of lean construction', Design and construction: Building in value, pp. 211-26.

Latham, S.M. 1994, Constructing the team, HM Stationery Office.

Lichtig, W.A. 2010, 'The Integrated Agreement', Improving Healthcare through Built Environment Infrastructure, p. 85.

Love, P.E., Teo, P. \& Morrison, J. 2017, 'Revisiting quality failure costs in construction', Journal of Construction Engineering and Management, vol. 144, no. 2, p. 05017020. 
Luth, G.P. 2011, 'VDC and the Engineering Continuum', Journal of Construction Engineering and Management, vol. 137, no. 10, pp. 906-15.

Mattessich, P.W. \& Monsey, B.R. 1992, Collaboration: what makes it work. A review of research literature on factors influencing successful collaboration, ERIC.

Mryyian, M. \& Tzortzopoulos, P. 2013, 'Identifying sources of design error in the design of residential buildings', 21st Annual Conference of the International Group for Lean Construction 2013, IGLC 2013, pp. 443-52.

Naar, L., Nikolova, N. \& Forsythe, P. 2016, 'Innovative construction and the role of boundary objects: a Gehry case study', Construction management and economics, vol. 34, no. 10, pp. 688-99.

Nguyen, H.V., Lostuvali, B. \& Tommelein, I.D. 2009, 'Decision analysis using virtual first-run study of a viscous damping wall system', Proceedings for the 17 th Annual conference of the international group for Lean construction.

Ostrom, E. 1998, 'A behavioral approach to the rational choice theory of collective action: Presidential address, American Political Science Association, 1997', American political science review, vol. 92, no. 1, pp. 1-22.

Parrish, K., Wong, J.-M., Tommelein, I.D. \& Stojadinovic, B. 2007, 'Exploration of set-based design for reinforced concrete structures', 15th Annual Conference of the International Group for Lean Construction IGLS, vol. 15, Citeseer, pp. 18-20.

Powell, W.W. 1990, 'NEITHER MARKET NOR HIERARCHY', Research in Organizational Behavior, vol. 12, pp. 295-336.

Pulaski, M.H. \& Horman, M.J. 2005, 'Organizing constructability knowledge for design', Journal of construction engineering and management, vol. 131, no. 8, pp. 911-9.

Ring, P.S. \& Van de Ven, A.H. 1994, 'Developmental processes of cooperative interorganizational relationships', Academy of management review, vol. 19, no. 1, pp. 90-118.

Schöttle, A., Haghsheno, S. \& Gehbauer, F. 2014, 'Defining Cooperation and Collaboration in the Context of Lean Construction', 22nd Annual Conference of the International Group for Lean Construction, ed. B.T. Kalsaas, Koskela, L. \& Saurin, T.A., Oslo, Norway, pp. pp 1269-80.

Smith, J. 2010, Developing effective construction documents : lessons and case studies in constructability, Santa Monica, Calif. : Construction Analysis and Planning.

Sødal, A.H. 2014, 'Early contractor involvement: advantages and disadvantages for the design team', Institutt for bygg, anlegg og transport.

Staub-French, S. \& Khanzode, A. 2007, '3D and 4D modeling for design and construction coordination: issues and lessons learned', ITcon, vol. 12, pp. 381-407.

Thomsen, C., Darrington, J., Dunne, D. \& Lichtig, W. 2009, 'Managing integrated project delivery', Construction Management Association of America (CMAA), McLean, VA.

Thomson, A.M. 2003, 'Collaboration: Meaning and measurement'.

Thomson, A.M. \& Perry, J.L. 2006, 'Collaboration processes: Inside the black box', Public administration review, vol. 66, pp. 20-32.

Wood, D.J. \& Gray, B. 1991, 'Toward a comprehensive theory of collaboration', The Journal of Applied Behavioral Science, vol. 27, no. 2, pp. 139-62.

Zimina, D., Ballard, G. \& Pasquire, C. 2012, 'Target value design: using collaboration and a lean approach to reduce construction cost', Construction Management and Economics, vol. 30, no. 5, pp. 383-98. 